\title{
As interfaces entre a Geografia e as Políticas Públicas
}

\section{Interfaces between Geography and Public Policies}

\author{
Paulo Henrique de Carvalho Bueno ${ }^{1}$ \\ Antônia Jesuita de Lima²
}

\begin{abstract}
Resumo
Este artigo discute os possíveis diálogos entre a Geografia e as Políticas Públicas, tomando como referência analítica a Agenda 2015, de Teresina (PI), e a literatura sobre a temática. Entende-se que as materializações espaciais são fruto das interrelações dialéticas entre sociedade e natureza; com efeito, as políticas públicas empreendidas sobre um dado espaço (re)constroem práticas socioespaciais, que tomam corpo nas formas e conteúdos do mesmo. Destarte, ao analisar a produção espacial de uma realidade, pode-se fazer uso de decisões tomadas pelos entes governamentais que (des)conformam a realidade social existente, evidenciando os diálogos possíveis entre a Geografia e as Políticas Públicas.
\end{abstract}

Palavras-chave: Geografia. Políticas Públicas. Espaço Geográfico.

\begin{abstract}
This article discusses the possible dialogue between Geography and Public Policy, taking as reference analytical Agenda 2015 of Teresina (PI) and the literature on this subject. It understand that the embodiments are the result of spatial interrelationships between society, nature and society, so the policies undertaken over a given space (re) construct socio-spatial practices that take shape in forms and contents. Thus, when analyzing the production space of a reality it can use decisions made by governmental entities that (dis) conform to existing social reality, showing the possible dialogues between Geography and Public Policy.
\end{abstract}

Keywords: Geography. Public Policy. Geographical Space.

\section{INTRODUÇÃO}

As complexidades encerradas nos problemas cotidianos requerem das ciências uma postura dialógica entre vários ramos do conhecimento, respeitando as especificidades de cada campo disciplinar. Nesse sentido, supõe-se que as interfaces entre a geografia e as políticas públicas podem auxiliar na análise das problemáticas humanas, como no caso das questões urbanas. A suposição parte da ideia de que as ações empreendidas pelo poder público se materializam sobre o

\footnotetext{
${ }^{1}$ Instituto Federal de Educação, Ciência e Tecnologia do Piauí (IFPI). Professor de Geografia do IFPI. E-mail:ph21bueno@hotmail.com.

2 Universidade Federal do Piauí (UFPI). Professora doutora associada ao Programa de Pósgraduação em Políticas Públicas e ao Departamento de Serviço Social. E-mail: a.je.I@uol.com.br.
}

Esta obra foi licenciada com uma Licença Creative Commons - Atribuição 3.0 Não Adaptada. 
espaço, territorializando-se e imprimindo transformações nas diversas dimensões das vidas contidas no território.

Este artigo procura analisar as complementaridades entre a geografia e as políticas públicas, vislumbrando como os processos de sua formulação e execução podem configurar, reconfigurar ou desconfigurar os (re)arranjos de produção espacial. Destarte, busca-se evidenciar as articulações possíveis entre esses dois campos disciplinares: a ciência geográfica, com suas análises acerca das espacialidades das produções humanas impressas em formas que, dotadas de conteúdos, conferem-Ihe significações; e as políticas públicas, que se corporificam em decisões dos agentes públicos, que promovem modificações na realidade e fomentam mudanças nas produções espaciais. Nesse intento, parte-se do entendimento que

[...] as políticas públicas repercutem na economia e nas sociedades, daí por que qualquer teoria da política pública precisa também explicar as interrelações entre Estado, política, economia e sociedade. Tal é também a razão pela qual pesquisadores de tantas disciplinas - economia, ciência política, sociologia, antropologia, geografia, planejamento, gestão e ciências sociais aplicadas - partilham um interesse comum na área e têm contribuído para avanços teóricos e empíricos (SOUZA, 2006, p. 6).

No campo interdisciplinar, encerrado nos estudos das políticas públicas, a geografia pode contribuir com o estudo das espacialidades das ações humanas. É que, como diz Santos (2006, p. 13), “a geograficidade se impõe como condição histórica", pois

[...] nada considerado essencial hoje se faz no mundo que não seja a partir do conhecimento do que é território. O território é o lugar em que desembocam todas as ações, todas as paixões, todos os poderes, todas as forças, todas as fraquezas, isto é, onde a história do homem plenamente se realiza a partir das manifestações de sua existência. A geografia passa a ser aquela disciplina tornada mais capaz de mostrar os dramas do mundo, da nação, do lugar (SANTOS, 2006, p. 13).

É nesse âmbito que se pretende discutir, explorando uma categoria central na geografia, a produção do espaço e as políticas públicas, tomando como referência o documento resultante dos debates em torno da elaboração do Plano Diretor de Teresina (PD), intitulado "Teresina Agenda 2015 - Plano de Desenvolvimento Sustentável". 


\section{$1(\mathrm{Re})$ produção do espaço geográfico: uma breve análise}

A geografia, como campo de conhecimento científico reconhecido pela comunidade acadêmica, é algo recente, uma vez que the pode datar a instituição nas três últimas décadas do século XIX, tendo como fundadores os alemães Alexander Von Humboldt e Karl Ritter. De sua institucionalização aos dias atuais, a geografia tem passado por reformulações, com o aparecimento e com os abandonos parciais de correntes teórico-metodológicas e discussões acerca de seu objeto, embates, enfim, necessários e comuns a cada ciência. Em seus primórdios, a geografia se apoiou, assim como as demais ciências humanas, no positivismo, como chancela de reconhecimento, tendo sua trajetória discursiva, ao longo do tempo, sofrido mutações, em função de reformulações de pensamentos filosóficos e de transformações ocorridas no âmbito da sociedade, seja em aspectos ligados à economia, à política, à cultura e meio ambiente, seja em outras dimensões da vida social (MORAES, 2005).

O desenvolvimento do conhecimento geográfico da realidade, do final do século XIX aos dias atuais, resultou em uma ciência mais fundamentada, especialmente no que diz respeito ao seu objeto de estudo, o espaço geográfico, que pode ser analisado a partir de conceitos-chave, como o de paisagem, lugar, rede, região e território, o que permite ao pesquisador discutir as espacialidades das ações humanas sobre a superfície terrestre, da escala local à global (MORAES, 2005). Consoante Santos (2008), o espaço geográfico é constituído por um sistema de objetos e um sistema de ações:

[...] esses objetos e essas ações são reunidos numa lógica que é, ao mesmo tempo, a lógica da história passada (sua datação, sua realidade material, sua causação original) e a lógica da atualidade (seu funcionamento e sua significação presente). Trata-se de reconhecer o valor social dos objetos, mediante um enfoque geográfico. A significação geográfica e o valor geográfico dos objetos vêm do papel que, pelo fato de estarem em contiguidade, formando uma extensão contínua, e sistematicamente interligados, desempenham no processo social (SANTOS, 2008, p. 77-78).

Esses sistemas de objetos e de ações podem ser apreendidos a partir do binômio forma-conteúdo, o qual fornece elementos primordiais para as explicações das construções geográficas da realidade. As formas, do ponto de vista geográfico, 
não existem por si só, fazendo-se necessário que sejam dotadas de conteúdos, para que se possa considerar sua espacialidade ou mesmo existência como vida. Daí se afirmar que as formas são os objetos e as ações, os conteúdos presentes nas formas, de sorte que se pode pensar o espaço geográfico como a unidade indissolúvel do sistema de objetos e do sistema de ações, que carrega em sua (re)produção uma temporalidade e uma processualidade, enfim, conta a historicidade das ações humanas sobre a superfície terrestre.

A análise do presente, pautada nas ações passadas, instiga prognosticar o futuro, ou seja, permite planejar atos de (re)produção dos espaços geográficos tidos, de modo que o espaço constitui uma acumulação de tempos (SANTOS, 2008) impressos em suas formas. Imaginemos, por exemplo, a produção espacial de uma determinada fração espacial citadina, como a área de concentração dos prestadores de serviços de saúde. Suas formas podem ser visualizadas e descritas em suas ruas, clínicas, hospitais, laboratórios, lanchonetes, pontos de táxis e moto-táxis, casas de pensões, residências tradicionais, farmácias, bancas de vendedores ambulantes, estacionamentos, entre outros. Esses elementos, embora pareçam existir isoladamente, somente corporificam uma realidade geográfica quando lhes processam os conteúdos e lhes articulam dialeticamente seus fixos com seus fluxos. Logo, só podem ser apreendidos como produção espacial quando se analisam as conexões entre as formas presentes no espaço com seus conteúdos, os quais mantêm relações com as distintas escalas (local, estadual, regional, nacional e global), mantendo uma dialética com as internalidades e externalidades espacialmente materializadas.

A produção espacial das casas de pensão, conforme análise de Bueno (2008), ${ }^{3}$ explica-se pelas intermediações que fazem entre os usuários e os hospitais, as clínicas, os laboratórios e os demais elementos presentes na área concentradora de serviços de saúde. Assim, nesse desenrolar de ações sobre os objetos, tais estabelecimentos (re)constroem cotidianamente territórios e territorialidades, o que é percebido, por exemplo, nos direcionamentos dos clientes a determinados estabelecimentos, em detrimento de outros, nas formas pelas quais os usuários

3 Bueno (2008) desenvolveu uma pesquisa sobre a produção espacial das casas de pensões presentes na área concentradora dos serviços de saúde teresinenses, analisando as (re)construções de territórios dos donos desses estabelecimentos nesse espaço e como se processa esse (re)fazer diário.

Cad. de Pesq. Interdisc. em Ci-s. Hum-s., Florianópolis, Santa Catarina, ISSN 1984-8951

v.15, n.106, p. 140-160 - jan./jun. 2014 
chegam até os locais de hospedagem, nas maneiras de conquista, manutenção e ampliação da clientela.

Os processos de territorialização, desterritorialização e reterritorialização - TD-R (HAESBAERT, 2006) - podem ser aprendidos, sob essa ótica, quando se observa que antigas edificações, com funções residenciais, sofrem mutações, em termos de significações funcionais e de formas para responder a interesses comerciais de proprietários das pensões, que oferecem serviços de hospedagem a pacientes demandantes de atendimento de saúde.

Tal pressuposto das T-D-R sugere que são as significações, os usos sociais das formas que (re)produzem cotidianamente o espaço. Contudo, essas (re)produções espaciais não são homogêneas, mas se dão de forma seletiva, e envolvem processos que levam em conta aspectos políticos, econômicos, culturais e ambientais, que se materializam em espaços diferenciados, produzindo territórios díspares que se complementam e se conflitam em determinados momentos. As diferenciações de produções espaciais advêm das relações socioespaciais, que resultam no espaço geográfico, daí que

[...] tais relações são econômicas (relação sociedade-espaço mediatizada pelo trabalho), políticas (relação sociedade-Estado ou entre Estados-nação) e simbólico-culturais (relação sociedade-espaço via linguagem e imaginário). A força motriz destas relações é a ação humana e suas práticas espaciais (BRAGA, 2007, p. 71).

Essa compreensão denota que o espaço é socialmente produzido, sendo apropriado e transformado pela sociedade, conforme Lefebvre (apud BRAGA, 2007), numa tríplice dimensão: como espaço percebido, referente às práticas espaciais (produção e reprodução social numa relação dialética com o espaço); como espaço concebido, concernente às representações do espaço; e como espaço vivido, como espaço da representação. Entende-se, por conseguinte, que a (re)produção espacial é permeada por objetividades e subjetividades, o que coloca a necessidade de analisá-la de forma dialética. Destarte, apreender as inter-relações nas constituições do espaço parte da perspectiva de que

[...] todo um sistema de contradições assim implantadas no e a partir do espaço se instaura no âmbito da sociedade, o espaço instituindo-se e instituindo a sociedade como um campo de correlação de forças, a 
organização da sociedade se constituindo como uma determinação política por excelência (MOREIRA, 2006, p. 73-74).

Tal entendimento aponta para outra dinâmica das produções espaciais, representada pela díade localização-distribuição. Essa discussão binomial traz em seu bojo os prognósticos de intervenções sociais no espaço (sejam do poder público, sejam da sociedade civil), com vistas a uma regulação espacial ou um ordenamento territorial. Dessa forma, uma vez que

[...] localização e distribuição formam, sempre, um par dialético, isto é, contraditório, recíproco e indissociável, uma forma de regulação espacial é assim necessária no plano da organização da sociedade. O problema do ordenamento decorre do desdobramento dessa base. Conforme se apoie na referência da centralidade ou da alteridade do sistema das localizações, a sociedade se estrutura como uma sociedade de conflito ou de cooperação, mobilizando assim uma relação de regulação de conflito ou de regulação de cooperação [...]. A tensão espacial pede uma regulação. E a regulação espacial vem na forma de ordenamento do território (MOREIRA, 2006, p. 7, grifo nosso).

A ideia de ordenamento territorial passa pelo entendimento do território usado (SANTOS, 2008), pois é sobre ele que se dão as vivências humanas. Assim,

[...] o uso do território pode ser definido pela implantação de infraestruturas, para as quais estamos igualmente utilizando a denominação sistemas de engenharia, mas também pelo dinamismo da economia e da sociedade. São os movimentos da população, a distribuição da agricultura, da indústria e dos serviços, o arcabouço normativo, incluída a legislação civil, fiscal e financeira, que, juntamente com o alcance e extensão da cidadania, configuram as funções do novo espaço geográfico (SANTOS; SILVEIRA, 2003 , p. 21, grifo dos autores).

Tal pensamento põe em relevo a existência de um agente instituidor da regulação social, assim como de muitos elementos físicos constituintes das vivências diárias, o Estado. Compreende-se, então, que as políticas públicas, ao se materializarem sobre o espaço, acabam modificando os sistemas de objetos e os sistemas de ações, seja por construções de infraestrutura física, seja por criação de mecanismos de práticas da cidadania.

É nessa perspectiva dialética entre o poder público e a sociedade que se percebe o território como a extensão apropriada e usada de um dado espaço (SANTOS; SILVEIRA, 2003), sendo, como afirma Haesbaert (2006), o território definido por e a partir das relações de poder, desencadeadas na vida cotidiana. As relações de consensos e dissensos, presentes nas produções espaciais, advêm do 
fato de que o arranjo espacial pode ser concebido como um complexo de territorialidades, ou seja, um múltiplo de áreas configurativas com uma estrutura corológica, genética e genealogicamente densa de conflitos, e passível de intervenções que visem dar-lhe um ordenamento. Contudo, o ordenamento não é somente a estrutura espacial física, as formas presentes no espaço, mas a maneira como ela territorialmente se autorregula no todo das contradições da sociedade, de modo a mantê-la funcionando, segundo sua realidade societária (MOREIRA, 2006), no jogo das inter-relações dos sujeitos sociais, os quais interagem para erguer o território usado, dando conteúdo ao espaço (SANTOS, 2008).

Para a análise do território usado e suas territorialidades, inseridas em um sistema econômico, faz-se necessário relacioná-los com a esfera da produção em combinação com a da circulação, cada uma atuando de forma integrada e diferente, com a relação produção-circulação, variando no tempo, segundo a forma da acumulação (MOREIRA, 2006). Enfim, deve-se analisar a produção de uma dada realidade e suas interconexões com escalas diferentes, como a local, a regional, a nacional ou a global, vislumbrando-se os fluxos materiais e imateriais, presentes no território usado.

Pensar em desenvolvimento socioeconômico a partir da atuação do poder público, tendo como escala geográfica de atuação o território, remete a duas abordagens distintas: a) uma que considera fatores endógenos, focalizando as escalas local e regional; e b) outra, que leva em conta variáveis exógenas, fundamentada na escala nacional, distante do território vivido. Para Boisier (apud RÜCKERT, 2005, p. 87, grifo do autor),

[...] o primeiro fator do desenvolvimento endógeno refere-se ao processo decisional dos atores presentes na malha social do território. Os atores individuais são indivíduos que ocupam espaços na estrutura de poder; os corporativos são as instituições que representam interesses setoriais, de grupo, e os coletivos são os movimentos sociais, territoriais ou regionais. $O$ segundo fator do desenvolvimento endógeno são as instituições: os organismos de governo, as universidades e centros científicos, os serviços públicos, as empresas públicas, a imprensa, as associações de caráter associativo, os municípios e as ONGs. O terceiro fator é a cultura, no sentido da capacidade de produzir uma auto-referência, isto é, a capacidade para produzir a identificação da sociedade com seu próprio território. $O$ quarto fator são os procedimentos utilizados pelas diferentes instituições da área. O quinto fator são os recursos materiais, humanos, conhecimentos e psicossociais com que conta o território. Finalmente, o sexto fator é o entorno - meio externo, onde há uma multiplicidade de organismos sobre os quais não se tem controle.

Cad. de Pesq. Interdisc. em Ci-s. Hum-s., Florianópolis, Santa Catarina, ISSN 1984-8951

v.15, n.106, p. 140-160 - jan./jun. 2014 
As complexidades que envolvem o desenvolvimento endógeno, fruto das interpenetrações entre Estado e sociedade civil, são as verdadeiras forças atuantes da real tarefa de organização da sociedade, exercida por instituições como uma espacialidade diferencial (MOREIRA, 2006). Pode-se, assim, afirmar que

\begin{abstract}
A ação dos organismos superestruturais, que expressam tanto as funções formais do Estado (a sociedade política) quanto às demandas da sociedade civil, faz do arranjo do espaço um campo de correlação de forças, e do espaço um elemento de caráter essencialmente político em sua determinação sobre a organização global da sociedade. Faz também da sociedade assim espacialmente organizada um todo ao mesmo tempo de inércia e intenso movimento. Um aparente paradoxo que expressa o modo como se organizam e agem os diferentes sujeitos formadores da sociedade com seus diferentes interesses a partir de sua intervenção no espaço (MOREIRA, 2006, p. 83).
\end{abstract}

Moreira (2006) chama a atenção para os interesses contidos nas ações dos agentes construtores da sociedade, os quais ganham formas no espaço e em seus (re)arranjos, corroborando com a discussão de Corrêa (1989), em que destaca o crucial papel do Estado na organização da cidade, que varia no tempo e no espaço, segundo a dinâmica da própria sociedade. Logo,

\begin{abstract}
Uma primeira observação refere-se ao fato de o Estado atuar diretamente como grande industrial, consumidor de espaço e de localizações específicas, proprietário fundiário e promotor imobiliário, sem deixar de ser também um agente de regulação do uso do solo e o alvo dos chamados movimentos sociais urbanos. Assim, ao implantar uma refinaria de petróleo, o Estado está organizando diretamente o espaço urbano, ao mesmo tempo em que interfere, dada a natureza da atividade industrial, no uso da terra das áreas próximas [...]. No entanto, é através da implantação de serviços públicos, como o sistema viário, calçamento, água, esgoto, iluminação, parques, coleta de lixo etc., interessantes tanto às empresas como à população em geral, que a atuação do Estado se faz de modo mais corrente e esperado (CORRÉA, 1989, p. 24-25).
\end{abstract}

A atuação estatal visa, nessa perspectiva, à satisfação básica da população e à criação do alicerce para a (re)produção do capital, sendo a mesma "[...] marcada pelos conflitos dos diferentes membros da sociedade de classe, bem como da aliança entre eles" (CORRÊA, 1989, p. 26). É, pois, na relação entre Estado e sociedade, pautada na legitimação (via atendimento dos anseios sociais) e na acumulação (criação e manutenção das bases da produção capitalista), que são formuladas e implementadas as políticas públicas, as quais desenvolvem novos (re)arranjos espaciais, erguidos sobre a (re)construção de territórios, Cad. de Pesq. Interdisc. em Ci-s. Hum-s., Florianópolis, Santa Catarina, ISSN 1984-8951 v.15, n.106, p. 140-160 - jan./jun. 2014 
territorialidades, desterritorialidades e ordenamento territorial, constituindo-se em configurações espaciais, definidas nas relações de poder, e que emergem nas interrelações entre a sociedade, os processos e os arranjos governamentais, o que implica na (re)produção incessante do espaço geográfico. Essas interfaces entre a geografia e as políticas públicas constituem a construção textual seguinte.

\subsection{Interfaces entre a geografia e as políticas públicas: o caso da Agenda 2015}

O capitalismo traz no seu bojo algumas exigências ao Estado, a quem cabe instituir mecanismos para dar-Ihes legitimação social e alicerces para a (re)produção do processo de acumulação. De acordo com Offe (1984, p. 123), o Estado capitalista "[...] refere-se a uma forma institucional do poder público em sua relação com a produção material", que se submete a quatro determinações funcionais: 1) privatização da produção - condição em que o Estado está estruturalmente impedido de organizar, segundo seus critérios políticos, a produção de bens; 2) dependência dos impostos - o poder público depende, de forma indireta, do volume da acumulação privada, através dos mecanismos de tributação; 3) acumulação como ponto de referência - os detentores do poder têm como maior interesse manter as condições políticas que propiciem a acumulação privada do capital; e 4) legitimação democrática - o exercício do poder por meio de mecanismos representativos que repercutem na formação de vontades e regulamentação dos conflitos, de forma politicamente duradoura, mantendo, de modo estável, a delimitação da esfera privada e da liberdade econômica, como maneira de defender essa órbita de liberdade de possíveis interferências do Estado.

Entendendo-se essas condições de funcionamento do Estado, pode-se, segundo Offe (1984, p. 125), definir a "política" do Estado capitalista como "[...] um conjunto de estratégias mediante as quais se produzem e reproduzem constantemente o acordo e a compatibilidade de tais determinações estruturais", sendo-lhe o aspecto dinâmico da estrutura estatal, que produz a transformação da forma-mercadoria, na medida em que participa da solução dos problemas estruturais. É no momento de materialização dos aspectos dinâmicos do Estado, em que a economia, o Estado e a sociedade se inter-relacionam, que surge a política pública, concebida

Cad. de Pesq. Interdisc. em Ci-s. Hum-s., Florianópolis, Santa Catarina, ISSN 1984-8951 v.15, n.106, p. 140-160 - jan./jun. 2014 
[...] como o campo do conhecimento que busca, ao mesmo tempo, colocar o governo em ação e/ou analisar essa ação (variável independente) e, quando necessário, propor mudanças no rumo ou curso dessas ações (variável dependente). A formulação de políticas públicas constitui-se no estágio em que os governos democráticos traduzem seus propósitos e plataformas eleitorais em programas e ações que produzirão resultados ou mudanças no mundo real (SOUZA, 2006, p. 26).

As políticas públicas, campo de atuação estatal, afetam as mais variadas dimensões da sociedade, como as voltadas para a educação, para a saúde, para o uso e a ocupação do solo urbano, para o meio ambiente, dentre outros, materializando-se, assim, setorialmente. Segundo Offe (1984), tais ações estatais, sob um regime capitalista, buscam a transformação constante da forma-mercadoria, tornando-se, então, o ponto de equilíbrio do Estado capitalista, funcionando como elo entre as estruturas políticas e econômicas da sociedade capitalista, e sendo, ainda, a conexão da dinâmica geral da acumulação, uma vez que as relações de troca só podem ter durabilidade se pautadas na expectativa de uma produção lucrativa.

Para evidenciar as interfaces entre a geografia e as políticas públicas, tomase como base de análise o documento "Teresina Agenda 2015 - Plano de Desenvolvimento Sustentável", que foi transformado em Plano Diretor da cidade, pela Lei n. 3.151, de 23 de dezembro de 2002 (TERESINA, 2002), e reinstituído pela Lei n. 3.558, de 20 de outubro de 2006 (TERESINA, 2006), no qual se definiram os objetivos nas áreas políticas, econômicas, sociais e físico-ambientais, para orientar o município em seu desenvolvimento sustentável. Tomam-se com foco de análise as proposições na área da saúde. Busca-se discutir, a partir da análise de um instrumento de política urbana, como o poder público pode desencadear ações que (re)produzem os espaços geográficos, os territórios e as territorialidades.

A Agenda 2015 foi construída em um contexto mundial e nacional, que trouxe a preocupação com a necessidade das cidades repensarem sua organização e suas políticas públicas. Teresina se inseriu nessa ambiência, propondo e formulando a elaboração de um novo instrumento, norteador das ações do poder público no meio urbano (BUENO, 2008).

O projeto de elaboração da Agenda se iniciou com a realização do Congresso da Cidade, em agosto de 2001, e foi concluído em agosto de 2002, tendo como 
horizonte a temporalidade de 13 anos. Com efeito, o processo contemplou um Congresso inaugural, no qual se delinearam os estudos temáticos e a sistemática de elaboração do documento, que se pautou pelos seguintes eixos: "A Teresina que temos" (diagnóstico); "A Teresina que teremos" (cenários); "A Teresina que queremos" (visão de futuro); e "A Teresina que faremos" (estratégias e projetos). Seguiram-se os grupos de trabalho, seminários e o II Congresso da Cidade, com apresentação do documento final.

Convém destacar que a ideia de cidade, tida na Agenda 2015, pautou-se em uma concepção de espaço urbano como mercadoria (VAINER, 2000), a qual deveria ser planejada, com vistas a potencializar diversas áreas, particularmente, as consideradas prioritárias, do ponto de vista econômico, como o setor saúde da capital, identificando seus pontos fracos e fortes, típicos da metodologia do planejamento estratégico (AFFONSO, 2002). Logo, configura-se,

[...] o perfeito e imediato rebatimento, para a cidade, do modelo de abertura e extroversão econômica propugnado pelo receituário neoliberal para o conjunto da economia nacional: o mercado externo e, muito particularmente, o mercado construído pela demanda de localizações pelo grande capital é o que qualifica a cidade como mercadoria (VAINER, 2000, p. 80).

Assim, a ideia de cidade-mercadoria emerge de uma relação direta entre a configuração espacial urbana e a (re)produção do capital, o que não é novidade, mas se registra como novo, nessa fase do capitalismo, o fato de que as cidades passaram, elas mesmas, a serem geridas e consumidas como mercadorias (ARANTES, 2000). É nesse contexto que o modelo de administração estratégica, que focaliza centralmente a competitividade e as vantagens do mercado, ganha vigor. Enfim, as palavras - (S)trengths = Pontos Fortes; (W)eaknesses = Pontos Fracos; $(\mathrm{O})$ portunities $=$ Oportunidades e $(\mathrm{T})$ heaths $=$ Ameaças - se reforçam nesse discurso de pensar a cidade.

Assinala-se que essa visão foi repassada aos componentes dos grupos de debates sem muitas possibilidades para o contraponto. Destarte, os movimentos sociais se viram cerceados no debate, o que acabou configurando as reuniões com papel mais deliberativo e legitimador de objetivos, já previamente definidos (FAÇANHA; VIANA, 2012). Com efeito, 
[...] sob o signo da participação, a sociedade foi convocada para, durante um ano, elaborar a agenda urbana local. A ideia de um congresso da cidade supõe não só o encontro dos distintos segmentos sociais para discutir os problemas citadinos e definir estratégias para seu enfrentamento, mas também o confronto e mesmo o antagonismo de posições, uma vez que há interesses divergentes envolvidos na produção do espaço urbano, requerendo uma sistemática de debates construída coletivamente, de forma a permitir a exposição e o embate de ideias. Mas, no caso de Teresina, a preparação e a condução do processo ficaram sob o controle de um grupo restrito, constituído pelo consultor, técnicos da prefeitura e especialistas, o que contrariava o discurso e os pressupostos da gestão democrática, conforme preceitua o Estatuto da Cidade (LIMA, 2012, p. 369).

Nesse sentido, pode-se afirmar que a sociedade teve pouca participação na elaboração do plano, porquanto não encontrou espaço para apresentar suas proposições e posições sobre projetos de cidade e de sociedade, para um futuro próximo, o que fez da participação apenas uma figura ilustrativa ou restrita, o que é próprio da concepção do planejamento estratégico (MARICATO, 2000).

De fato, na elaboração da Agenda 2015, a participação teve um caráter apenas consultivo, uma vez que não houve intervenções diretas dos diversos segmentos sociais, nem de todas as representações sociais, ficando o debate restrito a especialistas e representantes de categorias profissionais e empresariais, ligadas às atividades urbanas. Essa condução dos trabalhos acabou por evidenciar "[...] uma visão tecnocrática e autoritária na condução da gestão pública e a resistência de elites políticas e técnicas de assimilarem as novas regras do jogo" (LIMA, 2012, p. 373).

Na elaboração do Plano, uma das dimensões fortemente trabalhadas foi a da saúde, a qual era parte importante dos 16 campos temáticos da Agenda 2015, o que se atribui pelo menos dois fatores: 1) Teresina, por ser a maior cidade do Estado e por possuir uma maior quantidade de equipamentos urbanos ligados aos serviços de saúde, tem atraído uma quantidade significativa de pessoas do Piauí e de outros Estados, tendo, porém, que resolver problemas persistentes, como a mortalidade infantil; e 2) a capital piauiense dispõe de uma rede médica, com tecnologia que a torna em centro de referência em algumas áreas da medicina, e conta com clínicas e hospitais, especialmente da rede privada, que formam um grande conglomerado e caracterizam a produção de seu espaço urbano (BUENO, 2008).

Destarte, entre os objetivos econômicos da Agenda 2015, figurou como meta a consolidação do Polo de Saúde, apresentado como o embrião da formação de um Cluster de Saúde, com a tessitura de uma cadeia produtiva e de serviços 
interligados, que trazem benefícios, em termos de redução de custos, melhoria de qualidade, formação de mão de obra qualificada, atração de capitais e geração de renda (TERESINA, 2002).

Percebe-se, portanto, um viés economicista no discurso sobre a Política de Saúde no município, dada a forte ênfase nos investimentos privados, em que se depreende que a intervenção estatal ensejaria o avanço do capital na produção espacial daquela área, com a instalação de mais hospitais, clínicas e laboratórios.

Para operar o desenvolvimento do referido Polo, o poder público municipal identificou alguns desafios a serem transpostos, como "[...] a gestão deficiente da disposição do lixo hospitalar, [...], limpeza, vigilância sanitária, pavimentação, saneamento, tráfego, transporte coletivo, estacionamento, locomoção de deficientes físicos, policiamento e iluminação, entre outros" (TERESINA, 2002, p. 20), que demandariam um reordenamento espacial, com implicações importantes nas práticas de seus agentes construtores, com efeito, no processo de produção e reprodução do território e de seus (re)arranjos espaciais.

Fica claro, então, o ideário que norteou o pensamento dos formuladores do documento, expresso nas considerações que veem no Polo de Saúde uma grande oportunidade para o desenvolvimento econômico (TERESINA, 2002). Essa matriz econômica, que orientou a formulação da Agenda 2015, ancora-se na ideia de que, na divisão de responsabilidades, cabe às empresas a geração de riquezas e de oportunidades de trabalho e à sociedade criar uma ambiência que favoreça os empreendimentos (VELOSO FILHO, 2002).

A partir da variável competitividade, os planejadores projetaram o cenário desejável com a conformação do Polo de Saúde. Nesse horizonte, Teresina é visualizada como um centro de excelência em serviços de saúde, um cluster consolidado e de empreendimentos competitivos, para cuja materialização se requer a melhoria dos serviços e a afirmação do Polo como atividade econômica (TERESINA, 2002). Para tanto, vislumbraram-se quatro programas:

1) estímulo à melhoria da estrutura física e dos estabelecimentos privados de saúde. Para este, atribuíram-se os seguintes objetivos: conscientizar os empresários da área de saúde da importância da contínua melhoria da estrutura física e dos equipamentos; estimular o compartilhamento de custos e riscos por meio de parcerias operacionais, com vistas à optimização da estrutura física e dos 
equipamentos, à criação de incentivos fiscais para a ampliação da estrutura física e à aquisição de equipamentos nacionais e importados; incentivar a oferta de linhas de crédito, por parte das instituições financeiras públicas e privadas, com condições especiais; e, por fim, tornar obrigatória a construção de rampas para facilitar o acesso de pacientes e deficientes físicos aos espaços de Saúde (TERESINA, 2002);

2) fomento às atividades econômicas do Polo. Este programa foi subdividido em dois projetos: o primeiro - Estímulo às Atividades Produtivas - objetivava incentivar a criação e ampliação de fábricas de medicamentos, de materiais médicohospitalares, de gases medicinais e de alimentos, assim como criar a central de esterilização de materiais e a lavanderia hospitalar; e o segundo - Sistema de Tratamento de Resíduos Hospitalares - buscava instituir um sistema de coleta, tratamento e destinação final dos resíduos hospitalares, de acordo com as normas técnicas vigentes (TERESINA, 2002);

3) melhoramento das áreas do Polo de Saúde. Este compreendia três projetos. O inicial - Modernização e Urbanização - visava construir uma identidade visual para o Polo de Saúde, colocando portais nas entradas e saídas, melhorando o paisagismo, a sinalização dos logradouros e a iluminação pública e padronizando a identificação das pensões e hotéis; alargar as calçadas; reformular o trânsito e criar alternativas de estacionamento para facilitar o acesso e o deslocamento dos usuários, priorizando as Ruas Artur de Vasconcelos, Coelho de Resende e Desembargador Pires de Castro; acrescentar ao Código de Posturas do Município de Teresina normas específicas para o Polo; e, por último, utilizar a estação ferroviária como área de expansão do Polo, sendo denominada de Estação Saúde. O segundo projeto - Higienização e Limpeza - objetivava promover a limpeza e conservação da área de modo permanente e planejar e executar um sistema de saneamento. E o terceiro - Melhorias nos Hotéis, Pensões e Comércio de Alimentos - objetivava orientar e fiscalizar o acondicionamento do lixo produzido por pensões e estabelecimentos que comercializam alimentos; instituir áreas para acomodar quiosques padronizados para os vendedores de alimentos; criar linhas de microcrédito para melhorias em pensões, hotéis e atividades afins; estabelecer programas de educação em higiene, administração e primeiros socorros para as pessoas que trabalham nas pensões e hotéis; conscientizar da importância da melhoria da estrutura física, com vistas à adequação às necessidades da população 
demandante; e aperfeiçoar e qualificar o sistema de fiscalização da vigilância sanitária; e

4) eventos da saúde. Este último constituía-se de cinco projetos: o primeiro Marketing Científico da Saúde - tinha como objetivo organizar um calendário de eventos médicos e científicos; o segundo - Feira Anual de Equipamentos MédicoHospitalares - visava à realização desse evento; o terceiro - Novo Centro de Convenções - almejava à construção de outro edifício, com maior capacidade; o quarto - Revista Teresina Saúde - visava à criação de uma publicação semestral para divulgar as potencialidades do Polo, em parceria com os meios de comunicações; e o quinto - Quiosques da Saúde - pretendia promover a construção de quiosques para a divulgação das ações do Polo de Saúde, em locais de grande circulação, como o aeroporto, a rodoviária e o centro da cidade (TERESINA, 2002).

Pela leitura das proposições relacionadas à dimensão Saúde na Agenda 2015, fica evidente o quanto o Estado pode intervir, no sentido de cristalizar determinados territórios, criar novos ou promover reconfigurações espaciais, uma vez que as políticas públicas agem sobre os sistemas de objetos e sistemas de ações.

Contudo, os projetos voltados para a área da saúde não se concretizaram em sua plenitude, e os problemas ou pontos fracos ainda se fazem presentes no espaço concentrador dos serviços de saúde da capital, conforme análise de Teles (2011). A partir dessa constatação, os agentes produtores, sob a direção do Serviço Brasileiro de Apoio às Micro e Pequenas Empresas (SEBRAE), formularam e estão em fase de implementação do "Plano estratégico do polo empresarial de saúde de Teresina: 2013/2015". Essa ação visa capacitar os gestores dos serviços da saúde privados, para uma melhor administração dos seus negócios, fortalecendo a cadeia produtiva do setor (SILVA, 2012).

Já em relação ao fomento às atividades econômicas do polo, vislumbra-se como medida mais significativa a criação da legislação para o tratamento dos resíduos hospitalares, instituído pelo Decreto n. ${ }^{\circ}$ 9.432, de 18 de Junho de 2009 (TERESINA, 2009). Por outro lado, os projetos voltados para os eventos de saúde também tiveram pouca aplicabilidade.

Costa (2014) faz uma análise acerca das transformações socioespaciais, ocorridas na área concentradora dos serviços de saúde de Teresina, no período de 
2000 a 2013, e conclui que: 1) predomina ainda nesse espaço uma infraestrutura deficitária quanto ao trânsito de veículos e de pessoas; 2) as casas de pensões continuam a ter as mesmas estruturas físicas; 3 ) o projeto voltado para os eventos de saúde não se efetivou; 4) mantêm-se presentes os vendedores ambulantes nas ruas, sem um espaço específico que os acomodem; e 5) os conflitos pela (re)produção de territorializações, desterritorializações e reterritorializações têm gerado problemas que envolvem os diversos sujeitos produtores desse espaço (donos de pensões, proprietários de hospitais, clínicas, laboratórios, farmácias, taxistas e moto-taxistas, agenciadores(as) de clientes para determinados estabelecimentos médicos, vendedores ambulantes e o Estado).

Nesse sentido, deduz-se que os dois circuitos da economia urbana dos países subdesenvolvidos (SANTOS, 2004) se concretizam no espaço concentrador dos serviços de saúde da capital piauiense, ou seja, se, por um lado, existem agentes produtores do espaço integrados às formas mais modernas de inserção nos setores econômicos, por outro, coexistem agentes que se inserem a partir de formas tradicionais, na busca de sobrevivência econômica, o que evidencia diferenciações socioespaciais (CARLOS, 2007; CORRÊA, 2007) no território dos serviços de saúde, localizados na área central de Teresina, como destacado em Bueno (2008).

É nessa direção que se afirma que as ações sobre o espaço geográfico, prevista nos programas da Agenda 2015, trazem e trarão, materializadas em sua completude, uma série de modificações espaciais, que abrangem desde a disposição das coisas físicas (as formas) até as práticas sociais (os conteúdos) que nesse espaço se desenrolam. Logo, do ponto de vista geográfico, cabe analisar as ações, os processos $\mathrm{e}$ as (re)funcionalizações que as políticas públicas desencadearão na área concentradora dos serviços de saúde. Enfim, "certamente, se há aqui alguma especificidade do conhecimento geográfico relativa às políticas públicas, ela está na dimensão espacial que permeia a temática [...]" (SERPA, 2011, p. 38). Sublinhe-se ainda que se deva buscar compreender as lógicas de todo esse processo de formulação e implementação das políticas públicas, em especial os grupos menos favorecidos, os socialmente excluídos e os inseridos informalmente nesse ramo de atividade. Expõe-se essa preocupação em função de que a ausência do Estado, por meio da regulação de muitas atividades, tem gerado conflitos na área, materializadas entre os sujeitos produtores do espaço urbano.

Cad. de Pesq. Interdisc. em Ci-s. Hum-s., Florianópolis, Santa Catarina, ISSN 1984-8951 v.15, n.106, p. 140-160 - jan./jun. 2014 


\section{Conclusão}

O espaço geográfico, (re)produzido pelas sociedades, constitui-se em sistemas de objetos e sistemas de ações, tendo dinâmicas que são motivadas por fatores internos e externos, as quais fazem com que desenvolvam (i)materialmente todas as dimensões humanas, apreendidas a partir da análise do território (re)construído por cada fração social.

As políticas públicas se materializam em um dado espaço, logo, elas interferem diretamente nas produções espaciais. A Agenda 2015, instituída como Plano Diretor da capital piauiense, sendo, portanto, um instrumento balizador do uso e ocupação do solo urbano teresinense, materializa esse pensar.

A análise desse documento, tomando como referência as proposições na área da saúde, teve o objetivo de pôr em evidência as interconexões existentes entre as ações do Estado e a produção do território a partir da formulação e implementação de uma política pública. Discutiu-se como os programas propostos para a promoção do desenvolvimento do Setor de Saúde enunciam a produção de novas dinâmicas socioespaciais, na área em que se concentram os serviços de saúde teresinense, implicando em ordenamentos territoriais necessários à regulação de conflitos ou de cooperações, o que interfere diretamente na (re)construção de territorializações, desterritorializações e reterritorializações (T-D-R).

Ora, os estudos geográficos podem utilizar conceitos e categorias analíticas das políticas públicas, como ferramentas que corroborem a análise das práticas espaciais humanas. Por outro lado, o campo das políticas públicas pode usufruir de formulações da geografia, para auxiliarem em suas construções teóricas e práticas, utilizando-se, por exemplo, das noções de espaço geográfico, território, territorialidades, desterritorialização, reterritorialização e ordenamento territorial, tão caros à ciência geográfica.

Uma das especificidades com que a geografia pode contribuir para as políticas públicas se centra, assim, na dimensão espacial, que permeia a temática. Dessa forma, conceitos, como escalas, território, poder, região, cultura, identidade e cidadania, constitui-se como vieses geográficos úteis nas análises das políticas públicas e em suas dialéticas, fundidas no espaço geográfico. Enfim, pode-se 
afirmar que, no sentido da leitura espacial da realidade e posteriores intervenções, a geografia oferece uma grande contribuição às políticas públicas, teorizando e revelando os aspectos que envolvem a (re)produção pela sociedade dos territórios. 


\section{REFERÊNCIAS}

AFFONSO, C. A. A. Planejamento estratégico e o Plano Agenda 2015. Scientia et Spes, Teresina, v. 1, n. 2, p. 71-92, 2002.

ARANTES, O. Uma estratégia fatal: a cultura das novas gestões urbanas. In: ARANTES, O.; VAINER, C. B.; MARICATO, E. (Orgs.). A cidade do pensamento único: desmanchando consensos. Petrópolis: Vozes, 2000. p. 11-74.

BRAGA, R. M. O espaço geográfico: um esforço de definição. GEOUSP: Espaço e Tempo, São Paulo, n. 22, p. 65-72, 2007.

BUENO, P. H. de C. As casas de pensões do pólo de saúde de Teresina: produção espacial e políticas públicas. 2008. 128f. Dissertação (Mestrado em Políticas Públicas) - Universidade Federal do Piauí, Teresina, 2008.

CARLOS, A. F. A. A diferenciação socioespacial. Revista Cidades, Presidente Prudente, v.4, n.6, p. 45-60, 2007.

CORREAA, R. L. Diferenciação socioespacial, escala e práticas espaciais. Revista Cidades, Presidente Prudente-SP, v.4, n.6, p. 61-72. 2007.

. O espaço urbano. São Paulo: Ed. Ática, 1989.

COSTA, J. K. B. da. Demandas por serviços de saúde e as transformações socioespaciais na área central de Teresina. 2014. Dissertação (Mestrado em Geografia) - Universidade Federal do Piauí, Teresina, 2014.

FAÇANHA, A. C.; VIANA, B. A. da S. Planejamento e gestão urbana em Teresina (PI): notas da Agenda 2015 como plano diretor. Revista Equador, v.1, n. 1. 2012. Disponível online em: <http://www.ojs.ufpi.br/index.php/equador/article/view/899>. Acesso em: 14 out. 2013.

HAESBAERT, R. Concepções de território para entender a desterritorialização. In: SANTOS, M. et al. Território, territórios: ensaios sobre o ordenamento territorial. Rio de Janeiro: DP\&A, 2006. p.17-38.

LIMA, A. J. de. Plano diretor participativo e os desafios da governança urbana no Brasil. Revista Textos \& Contextos, Porto Alegre, v. 11, n. 2, p. 362-375, ago./dez. 2012. Disponível online em:

<http://revistaseletronicas.pucrs.br/fass/ojs/index.php/fass/article/view/11837>. Acesso em: 14 out. 2013.

MARICATO, E. As ideias fora do lugar e o lugar fora das ideias. In: ARANTES, O.; VAINER, C. B.; MARICATO, E. (Orgs.). A cidade do pensamento único: desmanchando consensos. Petrópolis: Vozes, 2000. p. 121-192.

MORAES, A. C. R. Geografia: pequena história crítica. 20. ed. São Paulo: Ed. Annablume, 2005. 
MOREIRA, R. O espaço e o contra-espaço: as dimensões territoriais da sociedade civil e do Estado, do privado e do público na ordem espacial burguesa. In: SANTOS, M. et al (Orgs.). Território, territórios: Ensaios sobre o ordenamento territorial. 2. ed. Rio de Janeiro: DP\&A, 2006. p.43-71.

OFFE, C. Problemas estruturais do estado capitalista. Rio de Janeiro: Ed. Tempo Brasileiro, 1984.

RÜCKERT, A. A. Reforma do Estado, reestruturações territoriais, desenvolvimento e novas territorialidades. GEOUSP, Espaço e Tempo, São Paulo, n. 17, p.79 - 94. 2005.

SANTOS, M. A natureza do espaço: técnica e tempo, razão e emoção. 4. ed. São Paulo: EDUSP, 2008.

. O dinheiro e o território. In: SANTOS, M. et al (Orgs.) Território, territórios: ensaios sobre o ordenamento territorial. 2. ed. Rio de Janeiro: DP\&A, 2006. p.13-21.

O espaço dividido: os dois circuitos da economia urbana dos países subdesenvolvidos. 2. ed. São Paulo: EDUSP, 2004.

SANTOS, M.; SILVEIRA, M. L. O Brasil: território e sociedade no início do século XXI. 5. ed. São Paulo: Ed Record, 2003.

SERPA, A. Políticas públicas e o papel da geografia. Revista da ANPEGE, v. 7, n. 1, p. 37-47, out. 2011. Disponível em: <http://anpege.org.br/revista/ojs-

2.2.2/index.php/anpege08/article/view/149>. Acesso em: 30 mar. 2012.

SILVA, E. F. M. Plano estratégico do polo empresarial de saúde de Teresina/PI. Teresina: SEBRAE/PI, 2012.

SOUZA, C. Políticas públicas: uma revisão de literatura. Sociologias, Porto Alegre, ano 8, n. 16, jul./dez., p.20-45. 2006.

TELES, M. A. A. C. Diagnóstico do Polo empresarial de Saúde - Teresina/PI. Teresina: Ed. SEBRAE/PI, 2011.

TERESINA, PREFEITURA MUNICIPAL. Decreto $n^{\circ}$ 9.432, de 18 de Junho de 2009. Regulamenta o parágrafo único, do art. $5^{\circ}$, da Lei Complementar $n^{\circ} 3.610$, de 11 de janeiro de 2007 (Código Municipal de Posturas), para disciplinar o gerenciamento dos resíduos de serviços de saúde, no âmbito do Município de Teresina, e dá outras providências. Disponível em:

<http://www.teresina.pi.gov.br/portalpmt/orgao/SEMPLAN/doc/20100419-335-1416-

D.pdf>. Acesso em: 30 mar. 2012.

Lei n. 3.558 de 20/10/2006. Reinstitui o Plano Diretor de Teresina, denominado Plano de Desenvolvimento Sustentável - Teresina Agenda 2015, e dá 
outras providências. Disponível em: <http://www.teresina.pi.gov.br>. Acesso em: 23 jun. 2012.

Lei n. 3.151 de 23/12/2002. Reinstitui o Plano Diretor de Teresina, denominado Plano de Desenvolvimento Sustentável - Teresina Agenda 2015, e dá outras providências. Disponível em: <http://semplan.teresina.pi.gov.br>. Acesso em: 23 jun. 2012.

2002.

. Teresina Agenda 2015: Plano de Desenvolvimento Sustentável. Teresina,

VAINER, C. Pátria, empresa e mercadorias: notas sobre a estratégia discursiva do planejamento estratégico. In: ARANTES, O.; VAINER, C. B.; MARICATO, E. (Orgs.). A cidade do pensamento único: desmanchando consensos. Petrópolis: Vozes, 2000. p. 75-103.

VELOSO FILHO, F. de A. Teresina Agenda 2015: desenvolvimento econômico. Scientia et Spes, Revista Instituto Camilo Filho, Teresina, v. 1, n. 2, p.143-170, 2002.

Artigo:

Recebido em: 27/09/2013

Aceito em: 15/06/2014 